\title{
Oral Hygiene Practices and Caries Prevalence among 9-15 Years Old Ghanaian School Children
}

\author{
Ndanu TA ${ }^{*}$, Aryeetey $\mathrm{R}^{2}$, Sackeyfio $\mathrm{J}^{1}$, Otoo $\mathrm{G}^{3}$ and Lartey $\mathrm{A}^{3}$ \\ ${ }^{1}$ School of Medicine and Dentistry, College of Health Sciences, University of Ghana \\ ${ }^{2}$ School of Public Health, College of Health Sciences, University of Ghana \\ ${ }^{3}$ Department of Nutrition and Food Sciences, University of Ghana
}
${ }^{*}$ Corresponding author: Ndanu TA, School of Medicine and Dentistry, College of Health Sciences, University of Ghana, E-mail: tomandanu@chs.edu.gh

Citation: Ndanu TA, Aryeetey R, Sackeyfio J, Otoo G, Lartey A (2015) Oral Hygiene Practices and Caries Prevalence among 9-15 Years Old Ghanaian School Children. J Nutr Health Sci 2(1): 104. doi: 10.15744/2393-9060.1.404

Received Date: November 25, 2014 Accepted Date: February 05, 2015 Published Date: February 09, 2015

\begin{abstract}
Introduction: Good oral hygiene protects against oral diseases such as caries and gum infections. Twice daily tooth brushing with fluoride pastes and flossing are recommended to keep mouth clean and reduce plaque bacterial growth. Poor access to oral cleaning material and dental care services expose children from poor backgrounds to oral diseases.

Objectives: The study assessed oral hygiene practices and caries prevalence among school children.

Methods: A cross-section of 9-15 year old school children $(n=1,040)$ were randomly selected from private and public schools in Accra, Ghana. Oral hygiene and snacking habits were assessed by interview using structured questionnaire. Oral cleanliness and dental caries were assessed by oral examination by two calibrated dental surgeons. Silness and LÖe Plaque Index (PI) and Decay, Missing and Filled Teeth (DMFT) score were used to determine oral hygiene and caries status respectively.

Results: Mean age of sample was $12.01 \pm 1.52$ years. Overall caries prevalence was $17.4 \%$ but (19.9\%) in the public and (15.1\%) in the private schools. It was higher in the females (19.3\%) than the males (15.1\%) in both private and public schools. Almost all (96.6\%) brushed once a day. About $60.0 \%$ had plaque and $64.4 \%$ had supra gingival calculus. Overall mean DMFT score was $1.138 \pm 0.476$. Types of snacks taken in a day and weekly frequency of snacks were significantly higher in the private schools than in the public school children. Overall, oral hygiene status was acceptable in the children.

Conclusion: Oral hygiene practices and status were comparable in the private and public school. Snacking frequency was high in both groups but did not account for the differences in caries prevalence observed.

Keywords: Oral hygiene status; Snacking, caries prevalence; Public and private school children; DMFT score
\end{abstract}

\section{Background}

Dental caries and gum disease are the commonest oral diseases in children [1] and may be associated with severe pain [2-4]. The pain may interfere with food intake and affect the normal growth of the child $[1,5]$. Globally prevalence of dental caries are declining but the factors that predispose children to caries still persist [6]. These factors include high snacking habits and bad oral hygiene practices [7]. Studies have indicated that socio-economic factors are associated with caries prevalence in both adults and children $[4,8,9]$. Dental caries was shown to be most prevalent in school children from poorer families. These Children also, had greater number of untreated oral lesions $[10,11]$.

Dental Caries is an infectious disease caused by the acid produced by the fermentation of simple sugars by oral bacteria, chief of which are streptococcus mutans and lactobacillus species [12,13]. Although sugars are provided by the type of diet consumed especially in our snacks, its effect on caries shows only when it is accompanied by poor oral hygiene practices and resultant poor oral hygiene status $[14,15]$. Oral cleanliness is therefore a basic factor for good oral health especially in children. Poor oral hygiene leads to dental plaque formation [16,17]. Dental plaque, the soft adherent materials deposited on the tooth surface may consist of bacteria, desquamated epithelial cells and migrated polymorphonuclear leukocytes [18]. A study in suburban school children in Accra reported plaque accumulation of $90 \%$ in 5-6 year olds but 54\% in 9 year olds. [19]. Poor oral hygiene therefore allows the bacteria in the plaque to thrive and then ferment sugars in foods to produce acid that leads to dental caries.

Lack of good oral hygiene therefore becomes the single most important factor in determining the risk of caries especially in children. Frequent snacking on sugar foods such as soft drinks, candies, fruit drinks and high sugar fruits may increase the risk of caries in children [20,21]. Simple mouth cleaning practices can easily clear this sugar substrates and remove oral plaque, and reduce the incidence of the dental caries. Caries will occur when plaque $\mathrm{pH}$ levels drop below 5.5 due to increased acid production in the dental plaque from the fermentation of sugars in the foods consumed [22]. 
Some oral hygiene practices recommended for children include twice brushing with the appropriate dentifrice including fluoride containing pastes or gels. Chewing stick and sponge used by some rural homes also contain anti-bacteria substances which reduce activities of the bacteria in the mouth $[23,24]$.). Some children also use mouth rinses to reduce their risk of caries while most rural folks also use chewing stick or sponge. Caries remains the commonest oral challenges in children only second to gum diseases [25]. Oral hygiene is assessed by exploring the tooth surfaces for plaque and calculus. Just few studies on the oral hygiene and caries have been reported in Ghanaian school children. These studies indicated high levels of accumulation of plaque in school children (19). Private and public school were targeted to see if their socioeconomic background could influence the oral hygiene status of the two groups. Children who attend private schools where fees are higher, mostly come from higher socio-economic class.

\section{Objectives}

This study therefore seeks to determine and compare the oral hygiene practices and oral hygiene status in relation to caries prevalence among private and public school children 9-15 year in Accra, Ghana. It also examined the association of the caries with snacking behaviour.

\section{Material and Methods}

A cross-section of 1,040 school children aged 9-15 years were recruited for the study. There were 547 children from 8 randomly selected private schools and 493 of them from 5 randomly selected public schools in Accra. In each school two streams of classes were randomly selected by ballot and all children from primary classes 4 to Junior high School (JHS3) were screened. Dietary and snacking practices as well as oral hygiene practices were assessed using questionnaire. The dietary and snacking questionnaire was adapted from the ENDORSE Study questionnaire which examined the dietary and snacking behaviours of school children (29). The oral hygiene habit assessment was done by using an assessment form used by the University of Ghana Dental School for school oral health outreach programs. Oral examination was done by two calibrated dental surgeons. The calibration of the two examiners was by screening 10 children for caries from a school not included in the study sample and the results were compared. The oral examination required the use of mouth mirrors and dental explorers for probing all the tooth surfaces to identify caries and it was done under sun light. Decay, Missing and Filled teeth (DMFT) score was used to determine caries prevalence while Plaque and Calculus indices as well as Silness and LÖe Plaque Index was used to measure overall oral hygiene status. The index ranges from 0 , no plaque to 3, abundant accumulation of plaque at the gingival margin. DMFT score indicate the extent of the dental caries and a value of 0 implied caries-free status. Chi-squared test was used to compare the prevalence between the public and private schools but T-test assuming unequal variance was used to compare the means of DMFT score and Plaque index between public and private schools. Spearman's rank correlation was used to correlate age, DMFT score a highly skewed data and Silness and Loe plaque score. Significant level was set at $\alpha=0.05$. Analysis was done using SPSS version 20.

\section{Results}

\section{Demographic characteristics and carries experience of the school children}

Mean age for private schools was $11.49 \pm 1.67$ and for the public schools was $13.59 \pm 1.43$. In the public school, males were 230 (46.7\%) and female 263 (53.3\%) but for the private school males form 235 (43\%) and females 312 (57\%).

Overall caries prevalence among the public and privates schools were $15.1 \%$ and $19.9 \%$, respectively. Overall plaque score was positively and significantly correlated with age of the children in the private school, $\mathrm{R}=0.120, \mathrm{p}=0.005$ but was inversely correlated with the DMFT score, $\mathrm{R}=-0.063, \mathrm{p}=0.133$. DMFT score showed inverse relationship with age, $\mathrm{R}=0-0.31, \mathrm{p}=0.485$. But in the public school no significant correlation was shown between Age, DMFT score and the Sinless and LÖe Index. The correlation values for Age and Silness and LÖe plaque index; $\mathrm{R}=-0.031, \mathrm{p}=0.585$, Age and DMFT score, R=-0.017, $\mathrm{p}=0.701$ and for Silness and LÖe plaque index and DMFT score was $\mathrm{R}=0.036, \mathrm{p}=0.511$.

\section{Oral hygiene habits between private and public schools}

Oral hygiene habits reported by the school children included morning and night brushing with nearly all of them $96.6 \%$ indicating brushing in the morning. Less than half of the children brush at night, but significantly more of the private school children indicated brushing at night than the public school children, (Table 1). Significantly more of the private students brush twice a day than the public school children. The cleaning materials used by school children in private and public school were similar. Knowledge of floss was more common among the private school children than the public school children but relatively more of the public school children who knew about dental floss used it. The use of tooth pick was common among the school children. Significantly greater proportions of private school children have attended a dental clinic at least for some oral health care than the public school children. (Table 1). 


\begin{tabular}{|c|c|c|c|c|}
\hline Oral hygiene habits & $\begin{array}{c}\text { Private } \mathrm{N}=547 \\
n(\%)\end{array}$ & $\begin{array}{c}\text { Public N=493 } \\
n(\%)\end{array}$ & $\begin{array}{c}\text { Overall N=1040 } \\
n(\%)\end{array}$ & P-value \\
\hline Morning brushing & $526(96.2)$ & $479(95.2)$ & 1005(96.6) & 0.029 \\
\hline Night brushing & $231(42.2)$ & $162(32.2)$ & $392(37.7)$ & \\
\hline \multicolumn{5}{|l|}{ Frequency of brushing } \\
\hline Brush once a day & $279(51.7)$ & $300(63.0)$ & $579(55.7)$ & \multirow{2}{*}{$<0.001$} \\
\hline Brush more than once a day & $261(48.3)$ & $176(37.0)$ & $437(42.0)$ & \\
\hline \multicolumn{5}{|l|}{ Tooth cleaning materials } \\
\hline Toothpaste and brush & $515(94.1)$ & $470(95.5)$ & 985(94.7) & 0.318 \\
\hline Other materials (Chewing stick/sponge. etc) & $32(5.9)$ & $22(4.5)$ & $54(5.2$ & \\
\hline Knowledge of floss & $76(13.9)$ & $36(7.4)$ & $112(10.8)$ & 0.006 \\
\hline Floss use & $31(5.7)$ & $31(6.3)$ & $62(6.0)$ & 0.673 \\
\hline Use of tooth pick & $331(60.4)$ & $270(54.8)$ & $601(57.8)$ & 0.061 \\
\hline Dental visit & $164(30.2)$ & $67(13.3)$ & $231(22.2)$ & 0.002 \\
\hline
\end{tabular}

Table 1: Oral hygiene habits among private and public school children

\section{Snacking habits in the school children}

Table 2 shows the snacking habits of the school children. Snacking was common among the children and it occurs more frequently at school than at home. Fruit drinks, sweets, biscuits and cakes were significantly more commonly consumed among the private school than the public school children. Soft drinks were more easily available and accessible at home to the private school than the public school children. The way children feel when they drink soft drinks and the response of their parents when seen drinking soft drink did not differ for the children in either private or public schools. Frequency of daily snacking and the intake of soft drink in particular was significantly higher among the private school children than the public school children.

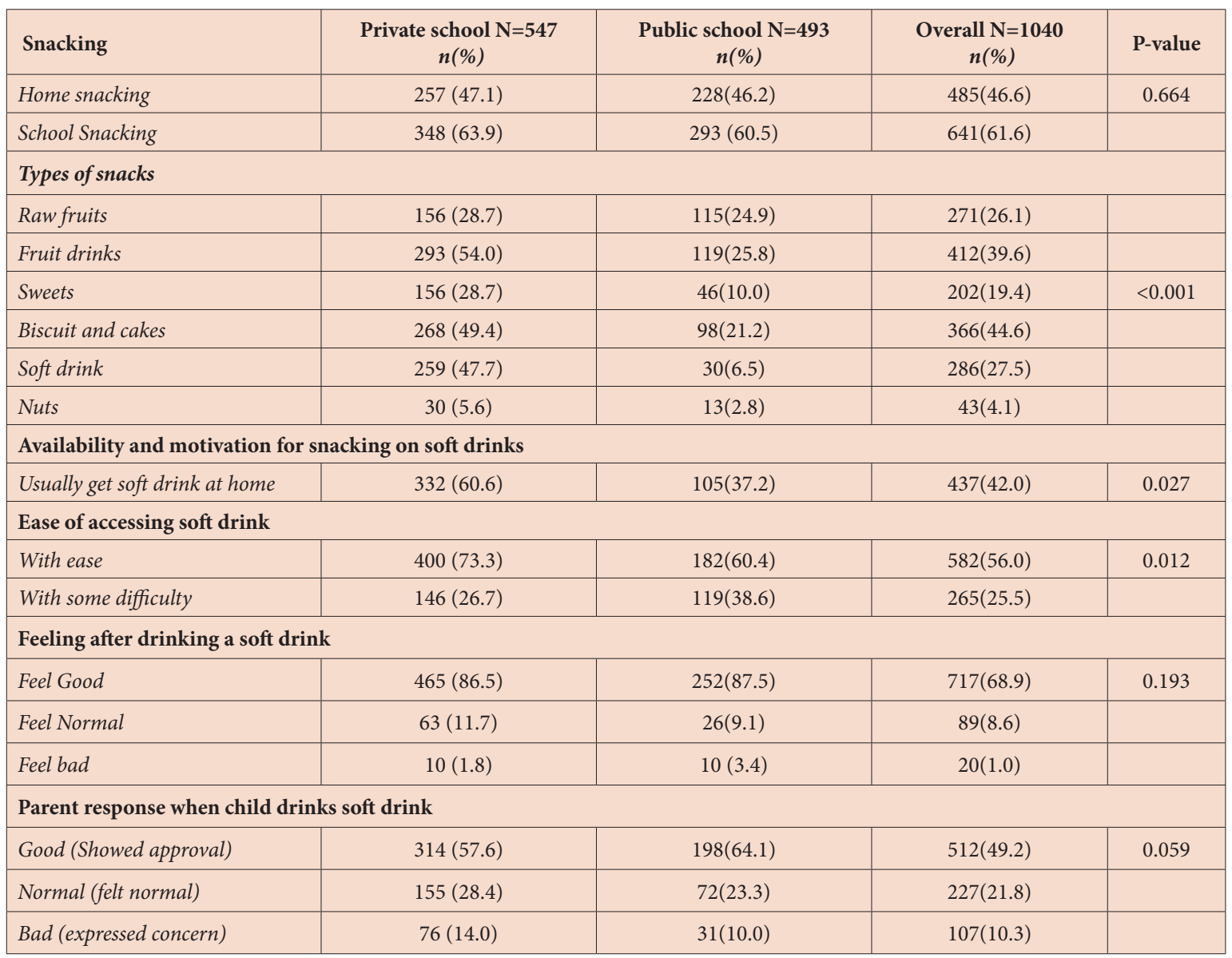




\begin{tabular}{|l|c|c|c|}
\hline Snacking & $\begin{array}{c}\text { Private school N=547 } \\
\boldsymbol{n}(\%)\end{array}$ & $\begin{array}{c}\text { Public school N=493 } \\
\boldsymbol{n}(\%)\end{array}$ & $\begin{array}{c}\text { Overall N=1040 } \\
\boldsymbol{n}(\%)\end{array}$ \\
\hline Frequency of snacking & Mean \pm SD & Mean \pm SD & P-value \\
\hline Days per week of snacking & $3.7 \pm 2.1$ & $2.83 \pm 2.14$ & $<0.001$ \\
\hline Average daily snacking & $1.14 \pm 0.42$ & $1.74 \pm 1.35$ & 0.002 \\
\hline Frequency of buying snacks & $1.89 \pm 1.70$ & $1.37 \pm 1.26$ & 0.004 \\
\hline Weekly intake of soft drink & $3.08 \pm 2.34$ & $1.63 \pm 1.54$ & $<0.001$ \\
\hline Average unit of soft drink per day & $1.97 \pm 1.98$ & $2.02 \pm 1.83$ & 0.709 \\
\hline
\end{tabular}

Table 2: Snacking habits among private and public school children

Oral hygiene status of the school children

Oral hygiene status is an indication of the cleanliness of the mouth. Comparison of the oral hygiene status between the private and public school children showed a significant poorer overall oral hygiene status in the private schools than in the public school children as shown in Table 3 below.

The oral hygiene status indicators showed significant higher scores in the private school than in the public school. Abundant plaque at the gingival margin showed worse condition among the private school than the public school. Subgingival calculus was more prevalent in the public school than in the private school children. The overall Silness and LÖe index shows that oral hygiene status was not very bad since the mean score was less than 1.5. This indicates that there were only mild to moderate accumulation of plaque film on the tooth surfaces which can easily be removed by effective tooth brushing. The low accumulation of the plaque and calculus also had little impact on the gum as heavy unilateral subgingival calculus was only $5.2 \%$. This led to just $1.6 \%$ of marked reddening and swollen gum in the children.

\begin{tabular}{|c|c|c|c|c|}
\hline Oral hygiene indicators & $\begin{array}{c}\text { Private school N=510 } \\
n(\%)\end{array}$ & $\begin{array}{c}\text { Public school } \mathrm{N}=493 \\
\mathrm{n}(\%)\end{array}$ & Total $N=1003$ & p-value \\
\hline \multicolumn{5}{|l|}{ Plaque score } \\
\hline $0=$ No plaque & $21(4.1)$ & $26(5.3)$ & $47(4.7)$ & \multirow[t]{3}{*}{$<0.0001$} \\
\hline $1=$ Barely visible plaque & $254(49.8)$ & $350(71.0)$ & $604(60.2)$ & \\
\hline $2=$ Abundant at gingival margin & $235(46.1)$ & $117(23.7)$ & $352(35.1)$ & \\
\hline \multicolumn{5}{|l|}{ Calculus score } \\
\hline $0=$ No calculus & $142(27.8)$ & $163(33.1)$ & $303(30.2)$ & \multirow[t]{3}{*}{$<0.0001$} \\
\hline $1=$ Supra gingival & $360(70.6)$ & $286(58.0)$ & $646(64.4)$ & \\
\hline $2=$ Subgingival heavy unilateral & $8(4.0)$ & $44(8.9)$ & $52(5.2)$ & \\
\hline \multicolumn{5}{|l|}{ Gingival score } \\
\hline $\begin{array}{l}0=\text { Pink, firm, stippled and no } \\
\text { exudates (normal) }\end{array}$ & $449(88.0)$ & $356(72.2)$ & $805(80.3)$ & \multirow[t]{3}{*}{$<0.0001$} \\
\hline $\begin{array}{l}1=\text { Shiny, slightly red and } \\
\text { swollen }\end{array}$ & $51(10.0)$ & $131(26.0)$ & $182(18.1)$ & \\
\hline $\begin{array}{l}2 \text { = Marked reddening, obvi- } \\
\text { ously enlarged, swollen with } \\
\text { exudates }\end{array}$ & $10(2.0)$ & $6(1.2)$ & $16(1.6)$ & \\
\hline Mean Silness and LÖe PI & $1.43 \pm 0.360$ & $0.930 \pm 0.364$ & $1.138 \pm 0.476$ & $<0.0001$ \\
\hline
\end{tabular}

Table 3: Oral hygiene Status among private and public school children

\section{Caries prevalence in the school children}

The caries prevalence as shown in Table 4, gave higher values in public school than in the private school children but was not significant. Only the mean DMFT score was significantly higher among the public school than the private school children. Even though the prevalence among the 12 year olds in the public school was about twice the values in the private schools the difference was not significant, $\mathrm{p}=0.0961$. Caries prevalence was higher in the females than the males in both private and public schools though not significant.

\section{Components of DMFT score}

The major component of the DMFT score was decay teeth which was about $80 \%$ of all the DMFT scores. Less than $5 \%$ of the score was due to filled teeth and less than $20 \%$ due to missing teeth. 


\begin{tabular}{|l|c|c|c|c|}
\hline \multicolumn{1}{|c|}{ Caries experience } & $\begin{array}{c}\text { Private } \\
\text { N (\%) }\end{array}$ & $\begin{array}{c}\text { Public } \\
\text { N (\%) }\end{array}$ & $\begin{array}{c}\text { Total } \\
\text { N (\%) }\end{array}$ & p-value \\
\hline $\begin{array}{l}\text { Caries prevalence in the entire } \\
\text { sample }\end{array}$ & $77(15.1)$ & $98(19.9)$ & $175(17.4)$ & 0.0946 \\
\hline Caries in the 12yr olds** & $10(11.4)$ & $9(25.7)$ & $19(15.4)$ & 0.0961 \\
\hline Male & $42(17.7)$ & $28(13.2)$ & $70(15.1)$ & \\
\hline Female & $59(22.2)$ & $49(16.6)$ & $108(19.3)$ & 0.479 \\
\hline Mean DMFT* score (Mean \pm SD) & $0.261 \pm 0.745$ & $0.543 \pm 1.146$ & $0.331 \pm 0.873$ & 0.019 \\
\hline \\
$\begin{array}{l}{ }^{*} \text { DMFT - Decayed, Missing and Filled Teeth; } \\
\text { **aries in 12 olds is used as prevalence of caries for the young population (WHO. 2002) }\end{array}$ \\
Table 4 : Prevalence of caries, and mean DMFT score \\
\hline
\end{tabular}

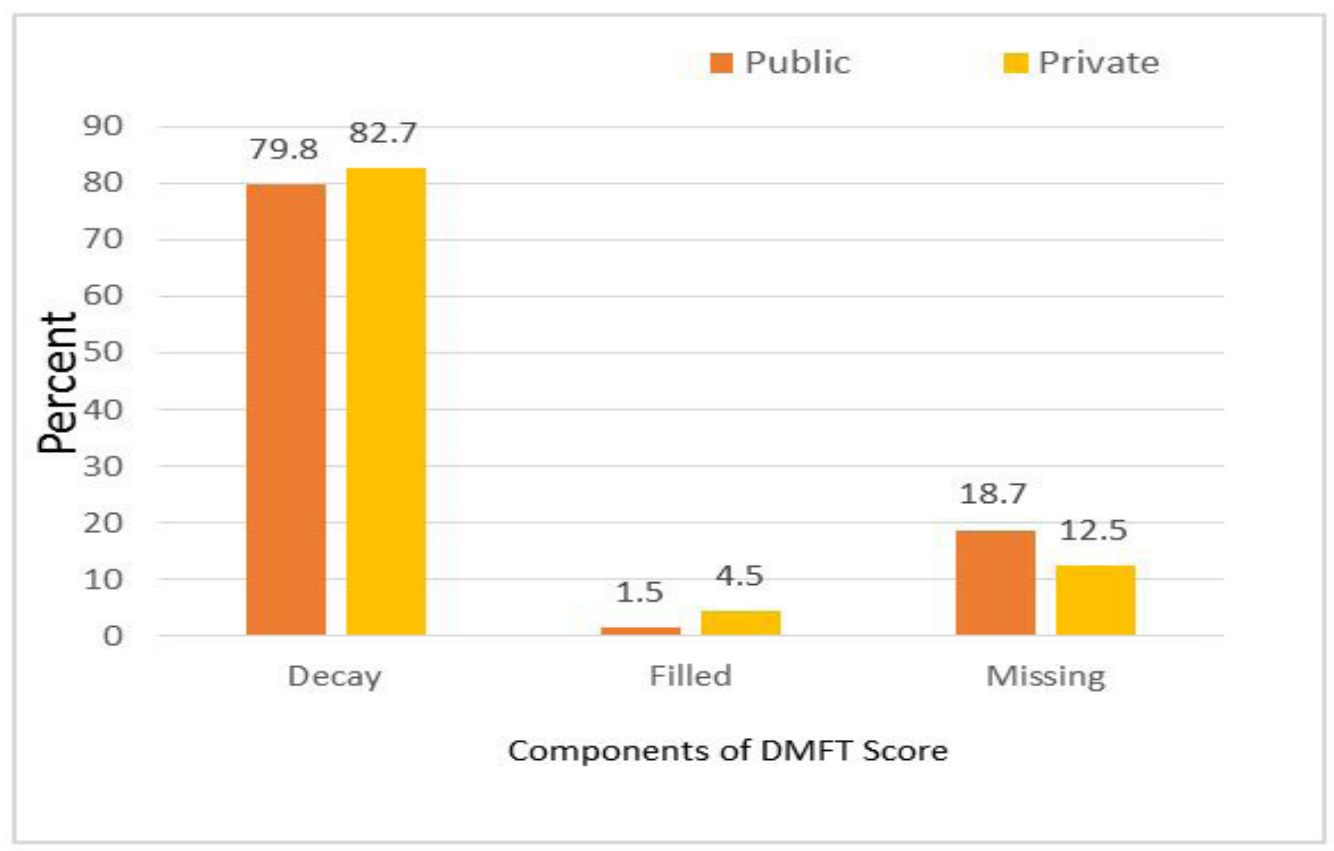

Figure 1: Component of DMFT score, $\mathrm{p}=0.102$

\section{Caries prevalence by age of school children}

Figure 2 below shows the caries prevalence by age. Caries prevalence was $28 \%$ in the 10 year olds compared to $18 \%$ in the 14 year olds for the public school children and then $23.8 \%$ in the 10 year olds and $5.2 \%$ in the 15 year olds for the private school children suggesting lower rates as age increases. The overall caries prevalence was higher in the public school than the private school but not significant. The highest prevalence was observed in the 10 year olds.

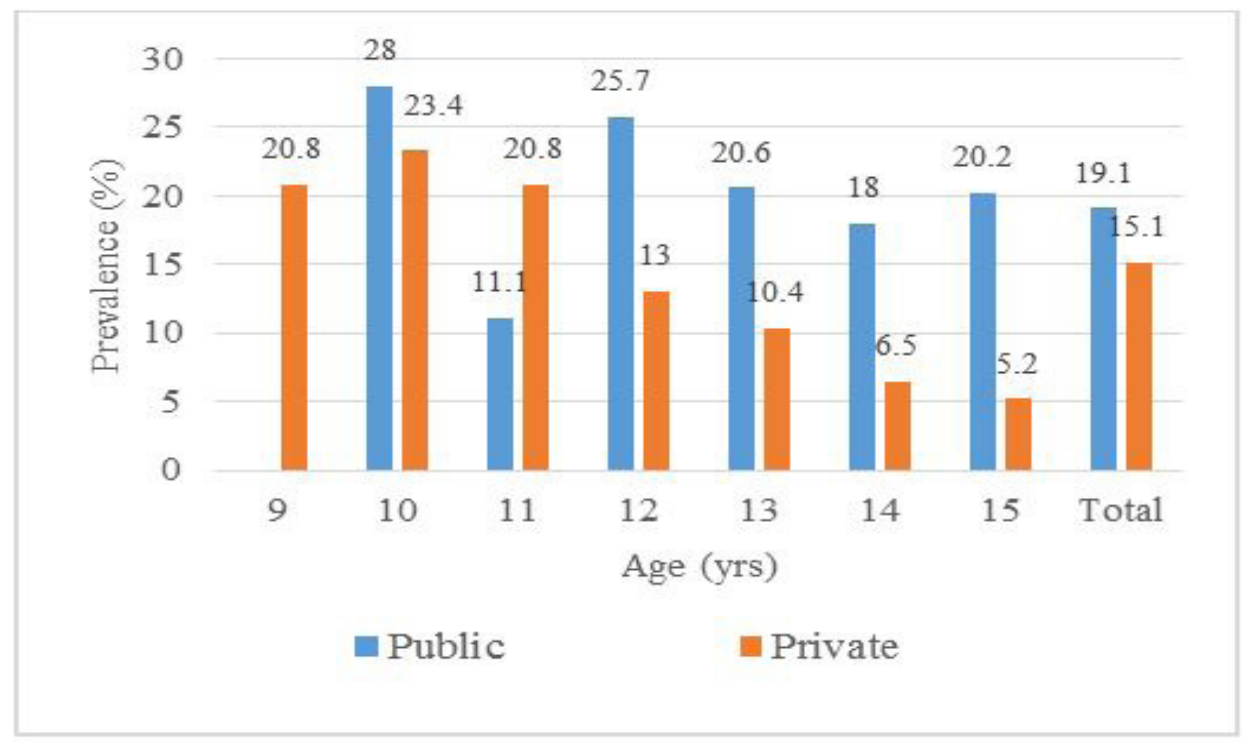

Figure 2: Caries prevalence among the age groups 


\section{Reported history of certain oral conditions in the school children}

Table 5 shows the results of comparison of history of certain oral conditions as reported by the children. Children in the private school are significantly more likely to have experienced the oral conditions. Just about $30 \%$ of all the children have ever visited the dental clinic for any oral health care. Almost all of those who attended reported with some oral health problem.

\begin{tabular}{|l|c|c|c|c|}
\hline \multicolumn{1}{|c|}{ Oral condition ever experienced } & $\begin{array}{c}\text { Private N=547 } \\
\mathbf{n}(\%)\end{array}$ & $\begin{array}{c}\text { Public N=493 } \\
\mathbf{n}(\%)\end{array}$ & $\begin{array}{c}\text { Total N=1040 } \\
\mathbf{n}(\%)\end{array}$ & p-value \\
\hline Dental visit & $164(30.2)$ & $135(26.8)$ & $299(28.8)$ & 0.355 \\
\hline Reported with oral condition & $159(98.8)$ & $108(83.1)$ & $267(25.7)$ & 0.008 \\
\hline History of Oral conditions & \multicolumn{5}{|l}{} \\
\hline Bad breath (halitosis) & $207(37.4)$ & $151(30.0)$ & $358(34.4)$ & 0.014 \\
\hline Gum bleeding & $287(45.6)$ & $232(46.1)$ & $519(49.9)$ & 0.082 \\
\hline Painful chewing & $331(60.7)$ & $194(38.6)$ & $525(50.5)$ & $<0.001$ \\
\hline Sensitive tooth & $356(65.4)$ & $279(55.5)$ & $635(61.1)$ & 0.005 \\
\hline Loss of teeth & $332(59.2)$ & $103(20.3)$ & $435(41.8)$ & $<0.001$ \\
\hline
\end{tabular}

Table 5: Dental visit and reported history of oral conditions

\section{Discussion}

The study investigated the oral hygiene habits and assessed oral hygiene status of the school children in relation to caries prevalence in both private and public basic schools. Similar oral hygiene habits and oral hygiene status were observed between the two school categories. Though caries prevalence was higher among the public school (19.9\%) than the private school children (15.1\%) this was not significant.

The oral hygiene status of the children showed that on average the children had mild to moderate accumulation of oral plaque which could be easily removed by regular effective tooth brushing. Less than $5 \%$ of the children had subgingival calculus, often due to prolonged poor oral hygiene. These results may account for the adequate oral hygiene status observed in the children.

Good oral hygiene practice is the most important factor that determines the overall oral health of the individual. It reduces the accumulation of plaque within which oral bacterial survive to produce acid that increase the risk of caries. Acquiring good oral hygiene habit early in life by the child does enhance good practices later in life [25]. This study suggests that the children practiced good oral hygiene as shown by the high level of mouth cleaning with the appropriate cleaning materials such as toothbrush and fluoride containing toothpaste. In addition many of them reported morning but fewer night brushing. Knowledge and use of dental floss was, however, limited among the children. Toothpick use was common and was similar in the private and the public school children. Wrong tooth pick use may damage the gum though it helps to remove food debris in the mouth reducing supply of substrates to the oral bacteria.

Snacking habits is the second most important factor in checking caries risk. This is only significant if accompanied by poor oral hygiene status [26]. The cariogenic snacks which included, fruit drinks, soft drinks, sweets and biscuits were consumed by significantly higher proportion of private than the public school children. This was expected because affordability may have favoured the private than the public school children. The adequate oral hygiene status observed among the children will render the snacking effect on dental caries less significant.

Plaque accumulation was worse in the private school than in the public school children. But Subgingival calculus was significantly higher in the public school than in the private school. Subgingival calculus gives an indication of prolong accumulation of plaques which becomes calcified.

The overall oral hygiene status as indicated by Silness and LÖe Plaque Index proved significantly higher in the private school than the public school children. This may be due to the abundant plaque at the gingival margin among the private school children. Poorer oral hygiene is expected to influence the overall caries prevalence but this was not observed in this study. Possible reason is that though the oral hygiene level was higher in one group than the other the overall status was not that poor to exert any significant effect on the caries prevalence.

The overall caries prevalence in the study population was higher among the public than the private school but was not significant. These values $15.1 \%$ for the private school and $19.9 \%$ for the public school children were far lower than prevalence reported among similar school population in other countries; Mexico was 48.6\% [27] and in Nigeria it was 35.5\% [28]

Severity of the caries as indicated by the DMFT score showed significant higher scores in the public than the private school children. This was also reflected in the higher prevalence of caries in the public school children. Decay component of the DMFT score was about $80 \%$, and fillings was less than $5 \%$ while missing teeth was about $15 \%$. This is indicative of low access and utilization of oral health care services as was also shown by dental clinic attendance below $30 \%$. Access to dental services would have enabled those cavities to be at least filled in the children. 
The study also showed very little correlation between the overall oral hygiene status and caries prevalence but showed significant positive correlations between overall oral hygiene status and age of the children in the private school children but not in the public school. Though caries prevalence was higher among the females than the males in both categories of schools it was not significant. Thus there was no significant sex disparity in the prevalence of caries.

The reported history of oral condition in the children showed that private school children had the propensity to experience oral conditions than the public school children.

\section{Conclusion}

Oral hygiene practices and consequent oral hygiene status was comparable in the public and private school children studied. There was slightly higher but non-significant caries prevalence in the public school than in private school though snacking was significantly higher among the private school children. Both age and sex did not have any significant impact on caries in the school children.

\section{Acknowledgement}

We wish to acknowledge the support of IDRC, for funding this study. We are grateful to the School of Medicine and Dentistry, (Dental Programme) for releasing equipment and personnel to carry out this study. We also wish to thank all the research assistants, the doctors and nurses who helped with this work. We wish to finally thank the school children and their head teachers who participated in the study.

We also wish to state that there is no conflict of interest to declare since no corporate interest funded this study.

\section{References}

1. Slade GD (2001) Epidemiology of dental pain and dental caries among children and adolescents. Community Dent Health 18: 219-27.

2. Barnes DE, Tala H (1987) Oral health trends in WHO African Region. Afr Dent J1: 2-4

3. yl, Global Data on Dental Caries Prevalence (DMFT) in children aged 12 years, Genenva: WHO.

4. Taani DQ (2002) Relationship of socioeconomic background to oral hygiene, gingival status, and dental caries in children. Quintessence 33: 195-8.

5. Sogi G, Bhaskar DJ (2001) Dental caries and oral hygiene status of 13-14 year old school children of Davangere. J Indian Soc Pedod Prev Dent19:113-7.

6. Cleaton-Jones P and Fatti P, (1999) Dental caries trends in Africa. Community Dent Oral Epidemiol 27: 316-20.

7. Palmer CA, Kent R, Loo CY, Hughes CV, Stutius, E, et al. (2010) Diet and caries-associated bacteria in severe early childhood caries. J Dent Res 89:1224-9.

8. duPlessis JB. (1997) The effect of socio-economic status on dental caries experience in 6, 12 and 15 year-old school children in Port Elizabeth and Despatch. J Dent Assoc S Afr 52: 483-6.

9. Sogi GM, Bhaskar DJ (2002) Dental caries and oral hygiene status of school children in Davangere related to their socio-economic levels: an epidemiological study. J Indian Soc Pedod Prev Dent 20:152-7.

10. French AD,Carmichael CL, Furness JA, Rugg-Gunn AJ (1984) The relationship between social class and dental health in 5-year-old children in the North and South of England. Br Dent J 156: 83-6

11. Jones CM, Woods K, Taylor GO (1997) Social deprivation and tooth decay in Scottish schoolchildren. Health Bull 55: 11-5.

12. Bradshaw DJ, Marsh PD (1994) Effect of sugar alcohols on the composition and metabolism of a mixed culture of oral bacteria grown in a chemostat. Caries Res 28: 251-6.

13. Bradshaw DJ, Marsh PD, Hodgson RJ, Visser JM (2002) Effects of glucose and fluoride on competition and metabolism within in vitro dental bacterial communities and biofilms. Caries Res 36: 81-6.

14. Barkeling B, Andersson I, Lindroos AK, Birkhed D, Rossner S (2001) Intake of sweet foods and counts of cariogenic microorganisms in obese and normal weight women. Eur J ClinNutr 55: 850-5.

15. Alm A (2008) On dental caries-related factors in children and teenagers. Swed Dent J Suppl 195: 7-63

16. Marinho VC, Higgins JP, Logan S (2003) Fluoride toothpastes for preventing dental caries in children and adolescents. Cochrane Database Syst Rev 4: CD002278.

17. Marinho VC, Higgins JP, Sheiham A, Logan S (2003) Fluoride toothpastes for preventing dental caries in children and adolescents. Cochrane Database Syst Rev 1:CD002278.

18. Harold Marcotte, Marc C. Lavoie (1998) Oral Microbial Ecology and the Role of salivary Immunoglobulin A. MicrobiolBiol Rev Mar 62: 71-109

19. Bruce I, Addo ME. Ndanu T (2002) Oral health status of peri-urban schoolchildren in Accra, Ghana. Int Dent J 52: $278-82$.

20. Ludwig DS, Peterson KE, Gortmaker SL (2001) Relation between consumption of sugar sweetened drink and child obesity: a prospective observational analysis. Lancet 357: 505-8.

21. Harnack L, Stang J, Story M (1999) Soft drink consumption among US children and adolescents: nutritional consequences. J. Am Diet Assoc 99: 436-41

22. Riva Touger-Decker and Cor van Loveren (2003) Sugars and dental caries. Am J ClinNUTR 78: 8881s-92s

23. Odongo, Charles Okot, Nathan LobuwaMusisi, Paul Waako, et al. (2011) Chewing stick practices using plants with anti Streptococcal activity in a Ugandan community. Front Pharmacol 2: 13.

24. Hong-Xi Xu, Sumaya Mughal, OluronkeTaiwo, Song F. Lee (2013) Isolation and characterization of an antibacterial biflavonoid from African chewing stick

-Garcia kola Heckel (Clusiaceae) Journal of Ethnopharmacology147: 497-502 
25. Judah G, Garddner B, Aunger R (2013) Forming a flossing habit: an exploratory study of the psychological determinants of habit formation. Br J Health psycho May 18: 338-53.

26. Axelsson P. and Lindhe J (1978) Effect of controlled oral hygiene procedures on caries and periodontal disease in adults. Journal of clinical Periodontology 2: $133-151$.

27. Pontigo-Loyola AP, Medina-Solis CE, Borges-Yanez SA, Patino-Marin N, Islas-Marquez A, et al. (2007) Prevalence and severity of dental caries in adolescents aged 12 and 15 living in communities with various fluoride concentrations J public Health Drnt Winter 67: 8-13.

28. Okoye LO and Ekweeme OC (2011) Prevalence of dental caries in a Nigerian Rural Community: A preliminary Local survey Ann Med Health Sci Res 1: 187195

29. Klazine van der Horst, AnkeOenema, Petra van de Looij-Jansen and Johannes Brug (2008) The ENDORSE study: Research into environmental determinants of obesity related behaviors in Rotterdam schoolchildren. BMC Public Health 8: 142.

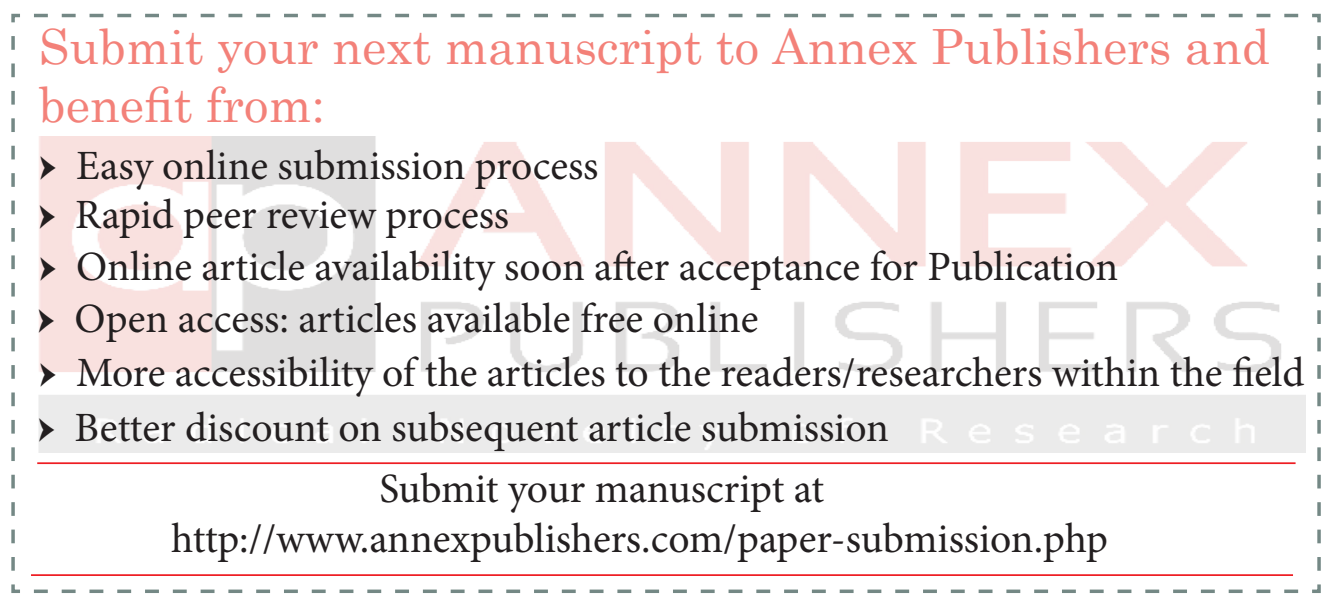

